\title{
Restricting Trade and Reducing Variety: Evidence from Ethiopia*
}

\author{
Pramila Krishnan \\ Department of International Development, University of Oxford and CEPR \\ pramila.krishnan@qeh.ox.ac.uk \\ Peng Zhang (corresponding author) \\ Beedie School of Business, Simon Fraser University \\ peng_zhang_7@sfu.ca \\ Mailing address: WMC 4323, Beedie School of Business, \\ Simon Fraser University, 8888 University Drive, \\ Burnaby, Canada, V5A 1S6 \\ Telephone number: +17787825545
}

November 11, 2018

Declarations of interest: none

\footnotetext{
${ }^{*}$ We thank Christian Dippel, Pascaline Dupas, Hamish Low, Simon Quinn and Stephen Redding whose comments significantly improved the paper and Jan Willem Gunning and Andualem Telaye for their collaboration on the project. We also thank Alessandro Tondini, Sara Tonini, and participants in Oxford Development Economics Workshop for helpful discussions, and Ibrahim Worku Hassen for help in cleaning the data. Financial support from the International Growth Centre Project Grant 89218 and the Cambridge Overseas Trust is gratefully acknowledged.
} 


\title{
Restricting Trade and Reducing Variety: Evidence from Ethiopia*
}

June 18, 2019

\begin{abstract}
The study of consumption in poor households usually focuses on the costs of the consumption basket rather than its composition. In contrast, we investigate the variety in consumption using unique data on a set of remote villages in northwestern Ethiopia. We examine the loss in variety in household consumption in remote locations, relying on a purpose-designed longitudinal survey over two years, where villages differ only in distance to the market and are homogeneous otherwise. In addition, we exploit a change in policy which resulted in a crackdown on informal, unlicensed traders in the second year and affected only the more remote set of villages. Variety in household consumption of manufactures falls with distance and time to travel to the main market town. The crackdown on informal traders, as a quasi-experiment resulting in an increase in travel costs, also leads to a relative decrease in variety consumed of manufactured goods for households served by the unlicensed traders.
\end{abstract}

Keywords: Variety; Transport costs; Africa; Ethiopia

JEL classification: D12, D04, O12, O18.

\section{Introduction}

Remoteness from markets imposes a variety of costs on rural households, including lower incomes, higher consumer prices and higher input costs in production. There is a large body of evidence to conclude that better access to markets raises incomes and well-being (Stifel et al., 2016; Stifel and Minten, 2017; Gollin and Rogerson, 2014), and that households that are better

\footnotetext{
${ }^{*}$ We gratefully acknowledge the financial supports from the International Growth Centre Project Grant 89218 and the Cambridge Overseas Trust. We would also like to thank seminar participants at the Universities of Cambridge and Oxford and two anonymous referees for their helpful comments.
} 
connected to urban centres have higher consumption and lower poverty (see for instance, Khandker et al. (2009); Dercon et al. (2009); Stifel et al. (2016); Jacoby (2000); Jacoby and Minten (2009); Stifel and Minten (2008); Dihel (2011)). An important reason is that better access in the form of roads and transportation lowers input costs and raises agricultural productivity, potentially raising farm incomes and household consumption.

There is now a substantial literature on the impact of transport costs and remoteness on these dimensions (Bird et al., 2010; Fafchamps and Shilpi, 2008) but in what follows we investigate the impact of such costs on variety in consumption or the range of goods in the household's consumption basket. Remoteness from markets affects the amount of consumption as established elsewhere but also potentially reduces the choice of varieties available in local markets, raising the costs of variety in consumption and thus lowering variety in consumption. As is usual in this literature, demonstrating the causal effect of transport costs on outcomes is complicated by the fact that roads and better infrastructure are often placed in areas of higher potential or actual productivity and countering this difficulty is vital (Adam et al., 2018; Donaldson and Hornbeck, 2016; Chamberlin and Jayne, 2013). In what follows, to examine the loss in variety of goods in remote locations, we use two quasi-experiments to separate the causal effect of transport costs from the confounding household characteristics. The first quasi-experiment is a purpose-designed survey to make sure villages differ only in distance to the market and are homogenous in key dimensions (see Stifel et al. (2016)). In particular, the setting offers a large variation in transportation costs over a relatively short distance but similar physical and climatic conditions across the villages surveyed. The purpose designed survey is identical in spirit to previous work to identify the benefits of rural roads and is drawn from an unique data source on remote villages in northwestern Ethiopia, where the villages are connected to the main market town only by mountain tracks (see Jacoby (2000); Jacoby and Minten (2009)).

To further consolidate the results, we use a second quasi-experiment by exploiting a change in a policy which resulted in a sudden and exogenous crackdown on informal or unregistered traders two years after the baseline survey. The implementation of regulations require retail traders to be licensed 1 . This affected only the more remote set of villages and resulted in a fall in availability there. In brief, we are largely able to counter the difficulty that roads and transport infrastructure might not be randomly placed in assessing the effect of remoteness on variety,

\footnotetext{
${ }^{1}$ The requirement for traders to obtain licenses (often by type of good, such as clothing, footwear or processed foods of different types) is not specific to this setting. Many countries in sub-Saharan Africa and elsewhere have such regulations in place (See Dihel (2011), Skinner (2008)).
} 
and in addition are able to use the crackdown on traders to assess the costs of raising barriers to trade alone. Chamberlin and Jayne (2013) discuss the fact that distances to town alone might not capture farmers' access to markets but the behaviour of marketing agents matters too.

In a parallel piece, Gunning et al. (2018) use data from a nationwide purpose-designed survey of shops and consumers in rural villages and market towns in Ethiopia to understand how remoteness reduces the variety of consumer goods available and the costs to consumers of fading choice. The focus there is on measuring the (loss in) availability of manufactured goods using data on traders who supply periodic markets and retailers in fixed village shops, relative to the full set of goods potentially available in the nearest market town. In this paper, we focus instead on the variety found in the consumption baskets of households. The particular setting we use allows us to measure the varieties actually consumed by households: the villages surveyed are laid out approximately on a line leading away from this market town. We see the main contribution of this paper as investigating the causal relationship between trade costs 2 (in particular, transport costs and fixed costs incurred by traders) that affect access to markets and variety in household consumption of manufactures, which is usually challenged by confounders such as household-level characteristics and the non-random placement of roads. The original survey was conducted by the International Food Policy Research Institute (IFPRI) in 2011 (see Stifel and Minten (2017) for details on the survey). As they emphasise, there are no roads in the area and the main differences between communities in the region are the transport costs between the villages and the main market town to which villagers travel, on foot (or donkey), using mountain tracks. Thus, transportation costs differ across villages not because of road placement but because of the physical geography of the region 3 . The aim of that initial survey was to ensure that transportation costs did not confound the causal assessment of market access on outcomes. The households in these villages were re-surveyed, two years later in 2014, after a crackdown on traders who operated without a license to sell manufactured goods came into effect in late 2013, thus allowing us to assess the impact of an exogenous and unexpected change in availability of goods on variety in consumption. Our focus is on household consumption and demand; thus the exogenous crackdown on traders which affects the supply of goods in remote

\footnotetext{
${ }^{2}$ Anderson and van Wincoop (2004) define these as "Broadly defined trade costs include all costs incurred in getting a good to a final user other than the marginal cost of producing the good itself: transportation costs (both freight costs and time costs), policy barriers (tariffs and non-tariff barriers), information costs, contract enforcement costs, costs associated with the use of different currencies, legal and regulatory costs, and local distribution costs (wholesale and retail)."

${ }^{3}$ On average, it takes households in the sample 4.5 hours to travel one-way during the dry season to the market town Atsedemariam (see Stifel et al. (2016)).
} 
villages helps us demonstrate the effect of the increased fixed costs of varietal marketing and is plausibly orthogonal to characteristics which determine the variety in consumption on the demand by households. In particular, we examine the variety in consumption of manufactured goods that are traded, and compare this with the variety in consumption of unprocessed food from home production. In this setting, the changes in variety in the consumption basket are rather more fundamental than an increase in say different brands of soft drinks; indeed, they are item groups such as processed food (like pasta), drinks including soft drinks and beers, clothing and fabric and so on. In summary, in this paper we focus on the demand side by studying how market access affects variety in household consumption, where market access is measured by travel costs to the central market, captured by travel time. As there are no roads at all, households must walk to the market on foot or with a donkey. Thus, the crackdown on informal traders lowers accessibility to variety of goods available locally.

The standard framework used to understand the gains from variety in international trade can readily be re-framed to understand the increased variety in consumption closer to the main market town in our setting. The basic intuition for the empirical analysis below derives from the standard trade framework (Melitz, 2003; Dixit and Stiglitz, 1977; Krugman, 1980, 1979). If each trader deals in a variety of good, then the set of varieties of goods available in each village should depend negatively on trade costs in the presence of a fixed cost per variety or fixed costs to traders dealing in a small set of products. As explained below, traders in Ethiopia must obtain a licence to carry different kinds of products which in turn imposes a fixed cost of carriage by item categories. There are also likely to be other fixed costs by location, including charges imposed by local village authorities for traders using village land and search costs of sourcing items in towns. In addition, it is plausible to assume that consumers do derive benefits from increased variety in their consumption basket. In this rather poor context such increased variety pertains for example to processed foods such as oils and flour; educational materials such as books and pencils; basic household goods such as plastic buckets and clothing and footwear. In what follows, we demonstrate the effect of increased costs of trade deriving from both travel costs and a change in the fixed costs of variety consumed by rural households.

Increasing costs of travel over space potentially have three main effects: first, an income effect since the value of income is likely to be lower with distance from market, a price effect since prices are likely to be higher with distance from market and last of all, a drop in varieties available, potentially due to fixed costs of providing varieties such as licensing costs as described 
above. These effects might well be low in many areas due to pro-competitive effects, but in the setting we examine, the geography and general remoteness from roads make entry of traders and goods difficult. $\mathrm{Li}(2017)$ is one of the few papers examining variety in consumption in a developing country and he documents an Engel curve for variety in food consumption using data from India, based on the notion that households might opt for more varieties to escape diminishing returns to quantity in a monotonous diet. Our approach focuses instead on the role of distance and travel costs to measure the variety in manufactured and processed goods in household consumption. The concentration on manufactures and processed goods allows us to assess their penetration in remote markets since this depends in good part on such travel costs. The interest in this issue is driven by the importance of examining the role of diversity in consumption in a high growth economy - Ethiopia has seen consistently high growth rates in this period and since 2006 has turned its focus from agriculture to the beginnings of industry. Eighty percent of the economy's population remains in agriculture and assessing the constraints to increasing domestic consumption of industrial goods and extending this market is of great interest.

The paper is organised as follows. In section 2 we introduce the data and the baseline purposeful survey that allows us to identify the effect of distance on variety. The next section explains a further quasi-experiment about a crackdown on unlicensed traders and discusses the corresponding empirical strategy and results. This is followed by a discussion of the robustness of the results while Section 4 concludes.

\section{Data and the Baseline Purposeful Design}

\section{$2.1 \quad$ Data}

The data used here come from the Ethiopia Rural Transport Survey, a longitudinal survey conducted in 2011 by IFPRI (see Stifel et al. (2016)) and repeated in 2014. The aim of the first round of the survey was to assess the benefits of feeder roads and the sample design was purposefully chosen to ensure that the main differences between villages were costs of travel to the nearest market town. They chose an extremely remote area in northwestern Ethiopia, Alefa district, approximately 100 kilometers from the city of Gonder. It is in a rugged terrain, west of Lake Tana and isolated with no roads or access to electricity and mobile telephony and all the households are engaged in farming. The average time to travel to the nearest market 

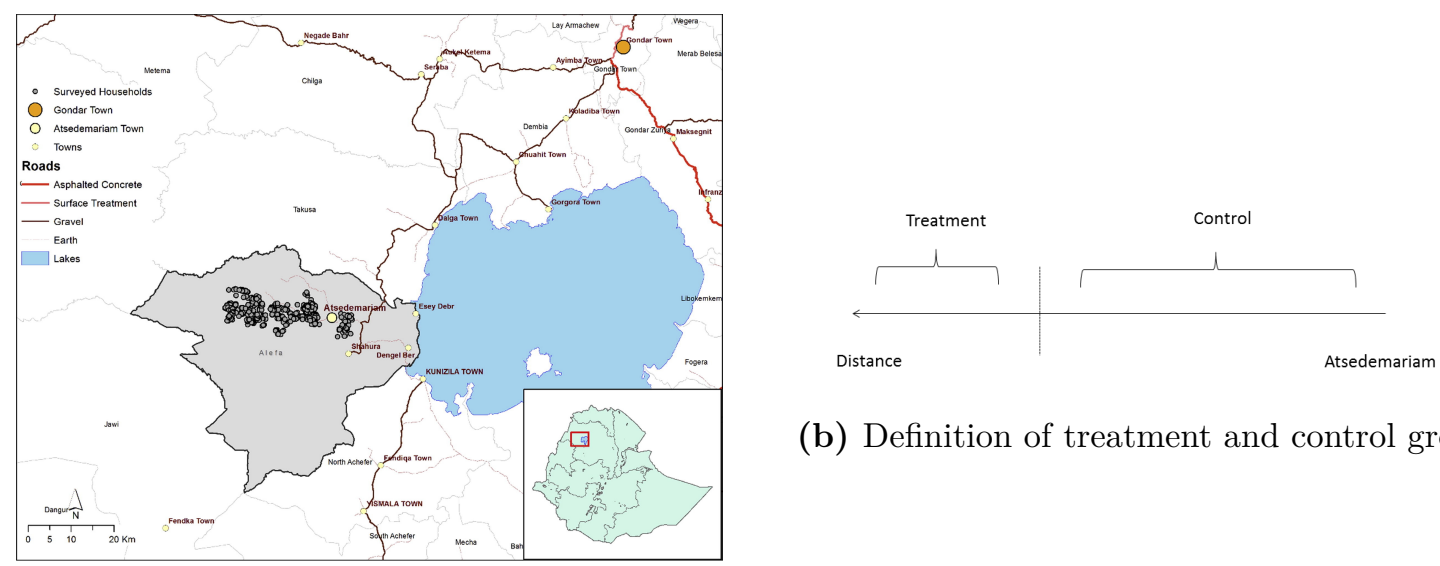

(b) Definition of treatment and control groups

(a) Map of the survey area

Notes: The left hand side plots the map of the survey area. The map comes from Stifel and Minten (2017). The red dots are households which are allocated along the road from Atsedemariam. The right hand side shows the definition of treatment and control groups. Treatment group is further away from Atsedemariam and is divided from the control group by a natural river.

Figure 1. A map of the survey area and the definition of treatment and control groups

town, Atsedemariam, is 4.7 hours. The key point is that the characteristics of land and its productivity are similar across the villages (Stifel et al., 2016) and consequently, the variation in outcomes such as household consumption can be thought to depend largely on behaviour driven by the variation in transport costs rather than the endowment of land. Note that given constraints on migration (households lose their right to land if they migrate), the distribution of households can be described as a (constrained) spatial equilibrium where returns to factors across space are attributable largely to transport costs.

The survey area covers 32 sub-subkebeles or hamlets (equivalent to villages) which belong to 7 sub-kebeles or sub-districts (Chimzen, Audir, Zehas, Dubaye, Garasghe, Avabehova, and Fantaye). All the households are located along the route between Atsedemariam and the most remote hamlet in Fantaye. One hundred and seventy households were surveyed in each of five different distance brackets from the main market town Atsedemariam, and these households are distributed relatively homogenously over this distance国. In all, 847 households were surveyed in 2011, while 775 were re-surveyed in 2014. A map of the survey area can be found in panel A of figure 1 .

The household survey gathered rich information on demographics, agricultural production, livestock, consumption, and travel cost. In particular, the survey gathers very detailed infor-

\footnotetext{
${ }^{4}$ As Stifel et al. (2016) state: "For sampling purposes, an equal number of households was interviewed in five different distance brackets (measured in travel time by donkey) from the market of Atsedemariam. 170 households were interviewed in each category, for a target of 850 households. Households were sampled evenly from subdistricts within each category to assure a relatively homogenous spread of households over the space between Atsedemariam and the most remote household in Fantaye. The sampling objective was to obtain a representation of households in the districts along the route from the market at Atsedemariam to Fantaye."
} 
mation on household food and non-food consumption. For both years there are records on 41 items of food expenditure and 32 items of non-food expenditure. For each item, households were asked about their frequency of purchase, quantity and amount of purchase of goods. Furthermore, detailed questions were asked about travel time with a loaded-donkey to Atsedemariam during both rainy and dry seasons. Information on the cost of renting a loaded-donkey from each respondent's house to Atsedemariam was also collected for both seasons. Other details about data and sampling process can be found in Stifel et al. (2016).

The variable of interest is variety, which is defined as the number of different items purchased by a household in each consumption category, with a focus on manufactured and processed items alone. Our main measure of remoteness or distance from market is travel time to Atsedemariam. Based on the data obtained directly from the information in the questionnaire on how long it takes to travel one way to Atsedemariam in the dry season, Stifel et al. (2016) calculate spatial moving averages of 5 nearest households to adjust for noise in households' self-reported values. We follow this approach and use the same measure to capture remoteness. Stifel et al. (2016) also offer an alternative measure of travel cost which is to calculate the monetary travel cost of the whole trip to Atsedemariam again based on a spatial moving average of 5 nearest households. As households carry goods by donkey and the transportation is rarely conducted by third parties (Stifel et al., 2016), the monetary cost here is a combination of cost of renting a donkey per kilogram and opportunity cost of travel time. The cost of renting a donkey per kilogram is based on the information in the questionnaire on the total cost of renting a donkey for a one-way trip to Atsedemariam and total number of kilograms a donkey carries for each trip. The opportunity cost of time is imputed by using the median harvest-period wage in the village. While we use this alternative measure as a robustness check, we rely on the simple measure of travel time rather than the monetary cost in the main analysis.

The average travel time in the dry season to Atsedemariam in the sample is 4.74 hours. The mean value of monetary cost (including opportunity cost of time) of a round trip is 76.26 birr (or $\$ 2.75)$. The rank order of hamlets is in an ascending order of travel cost. The closet hamlet to Atsedemariam is Mulalit, about 45 minutes away from Atsedemariam by donkey with a round trip cost of 18.8 birr (70 pence including the cost of renting a donkey and opportunity cost of time). The most distant village is Fantaye, 7.16 hours away from Atsedemariam on average by donkey, with a round trip cost of 102 birr or $\$ 3.70$. The data consist of a balanced panel of 717 households in 2011 and 2014. 
We examine the changes in consumption and variety both over time and across space. Our definition of manufactured goods comprises processed food such as sugar and cooking oil and non-food such as batteries, soaps, linens, fabric and ready-made clothing and footwear, all of which are sourced from the main market town Atsedemariam. A list of items in each category can be found in table 1. In the 2011 baseline data both the variety and expenditure decline with distance to Atsedemarim, as evident in figure 2, where we plot variety in consumption against a continuous measure of travel time (unit: hour). 


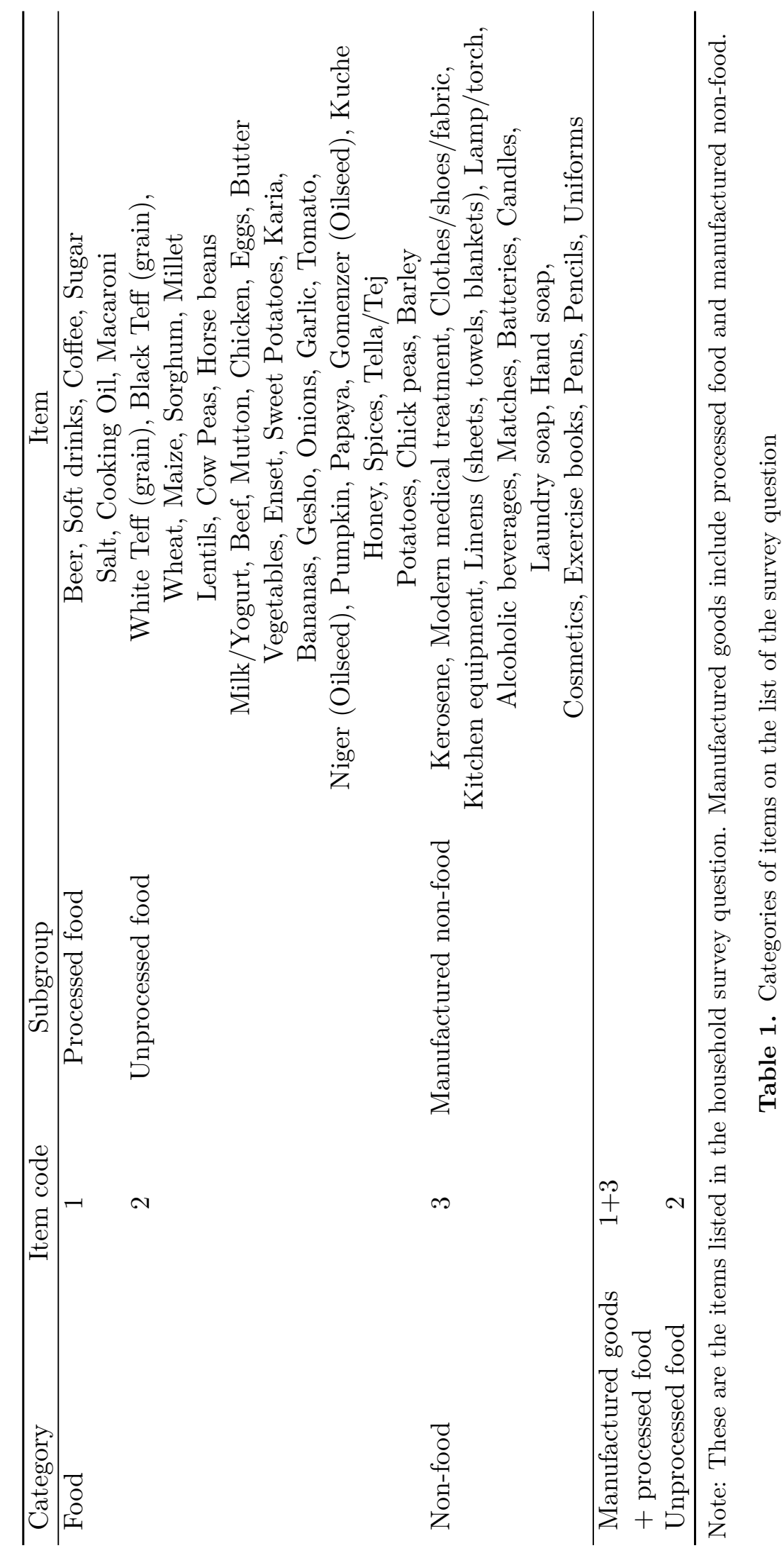






Notes: The figure captures the percentage of household with no consumption in manufactured items (we calculate whether the median household consumes each item in processed food and manufactured goods and average over the whole bundle) over distance to Atsedemariam (measured by travel time, unit: hour) in 2011 and 2014 data.

Figure 2. Median share of households not consuming manufactured items by travel time

\subsection{The effects of distance on variety using this purposeful survey}

To examine this pattern more formally, we run a regression of the number of varieties of manufactured items or unprocessed food consumed against travel time for 2011. Thus, we examine whether variety decreases with travel cost to Atsedemariam, given the purposeful design of the survey and conditional on the demographic characteristics of households 0 . The reasons for the fall of variety might of course be driven by reasons other than the costs of transport. Households in remote villages might differ from those close to the market town in various dimensions. For example, households further away from the market are likely to have lower incomes or different tastes for variety. These might reduce the number of varieties in their consumption bundles independent of transport costs. To deal with these household-level confounders, we compare the consumption of two different categories of goods: manufactured goods (including processed food) and unprocessed food. The same household consumes both types of goods but the variety in unprocessed food comes from home production and is therefore not dependent on travel costs. If the variety in household consumption is driven by transport costs rather than other household-level confounders, we should find that the variety in consumption decreases

\footnotetext{
${ }^{5}$ We postpone the examination of variety and travel time in 2014 to the next section, where we also examine the effect of a crackdown on traders.
} 
with distance or time to travel to the market town for manufactured goods but not unprocessed food.

The regression specification is as follows:

$$
Y_{i s}=\alpha+\beta C_{i s}+\phi X_{i s}+\epsilon_{i s}
$$

For each household $i$ in hamlet $s, Y_{i s}$ denotes variety in consumption (measured by number of different items purchased) in the main analysis; however, we also use expenditure as the dependent variable where we describe the effects on total consumption. $C_{i s}$ denotes travel time to Atsedemariam for household $i$ in sub-subkebele $s . X_{i s}$ refers to a set of control variables such as household assets (measured by the value of livestock), household size, number of male household members, number of teenagers (5-15 years old), the age of household head and quadratic terms of demographic controls. $\beta$ is the key parameter of interest.

Table 2 reports results of baseline OLS regressions of expenditure and variety of consumption on travel time for manufactured goods and unprocessed food, respectively with 2011 data. The dependent variable is amount of expenditure measured by birr in columns 1-2 and variety of consumption in columns 3-4. The independent variable of interest is travel time to Atsedemariam in all columns. The amount of expenditure, variety in consumption, travel time to Atsedemariam and value of livestock are in logs so the corresponding coefficients can be interpreted as elasticities.

The total expenditure on manufactured and processed goods in particular decreases significantly with increase in travel time to Atsedemariam, as is shown in columns 1 and 2 in table 2. A $1 \%$ increase in travel time to Atsedemariam is related to $0.51 \%$ decrease in amount of expenditure in 2011 for manufactured goods. Expenditure on unprocessed food is also responsive to changes in travel cost according to the results in column 2, which further confirms that overall household income decreases with travel time to the market town.

As travel time to Atsedemariam increases, variety in consumption of manufactured goods also decreases significantly, as is shown in column 3. A $1 \%$ increase in travel time is associated with $0.07 \%$ decrease in variety in 2011 baseline. In contrast, the variety of unprocessed food is not significantly correlated with distance to the central market in column 4 . In general, we would expect that expenditure on food is less price elastic than manufactured goods; this result tells us that variety is also less elastic in response to changes in prices, proxied here by 


\begin{tabular}{|c|c|c|c|c|}
\hline \multirow[b]{3}{*}{ VARIABLES } & \multicolumn{2}{|r|}{$[2]$} & {$[3]$} & [4] \\
\hline & \multicolumn{2}{|c|}{ Expenditure } & \multicolumn{2}{|c|}{ Variety } \\
\hline & $\begin{array}{c}\text { Manufactured } \\
+ \text { processed food }\end{array}$ & Unprocessed food & $\begin{array}{c}\text { Manufactured } \\
+ \text { processed food }\end{array}$ & Unprocessed food \\
\hline \multirow[t]{2}{*}{ Travel time } & $-0.509 * * *$ & $-0.425^{* *}$ & $-0.070 * * *$ & 0.035 \\
\hline & $(0.148)$ & $(0.186)$ & $(0.019)$ & $(0.064)$ \\
\hline \multirow{2}{*}{ Livestock value } & $0.143^{* * *}$ & $0.086^{*}$ & $0.041^{* * *}$ & 0.015 \\
\hline & $(0.032)$ & $(0.049)$ & $(0.014)$ & $(0.015)$ \\
\hline \multirow[t]{2}{*}{ No. of household members } & $0.252^{* *}$ & $0.222^{*}$ & $0.093^{* * *}$ & 0.013 \\
\hline & $(0.094)$ & $(0.125)$ & $(0.025)$ & $(0.052)$ \\
\hline \multirow[t]{2}{*}{ No. of male members } & 0.039 & -0.042 & $0.057^{* *}$ & 0.033 \\
\hline & $(0.081)$ & $(0.107)$ & $(0.026)$ & $(0.037)$ \\
\hline \multirow[t]{2}{*}{ Age of household head } & 0.015 & 0.038 & -0.001 & 0.013 \\
\hline & $(0.023)$ & $(0.032)$ & $(0.004)$ & $(0.009)$ \\
\hline \multirow[t]{2}{*}{ No. of teenagers } & -0.103 & -0.210 & 0.001 & $-0.086^{* *}$ \\
\hline & $(0.108)$ & $(0.132)$ & $(0.022)$ & $(0.041)$ \\
\hline \multirow[t]{2}{*}{ No. of household members sqr } & $-0.013^{* *}$ & $-0.014^{*}$ & $-0.006^{* * *}$ & -0.001 \\
\hline & $(0.006)$ & $(0.008)$ & $(0.002)$ & $(0.003)$ \\
\hline \multirow[t]{2}{*}{ No. of male members sqr } & -0.001 & 0.008 & $-0.007^{* *}$ & -0.004 \\
\hline & $(0.011)$ & $(0.012)$ & $(0.003)$ & $(0.004)$ \\
\hline \multirow[t]{2}{*}{ Age of household head sqr } & -0.000 & -0.000 & -0.000 & $-0.000^{*}$ \\
\hline & $(0.000)$ & $(0.000)$ & $(0.000)$ & $(0.000)$ \\
\hline \multirow[t]{2}{*}{ No. of teenagers sqr } & 0.012 & $0.051^{* *}$ & 0.003 & $0.016^{* *}$ \\
\hline & $(0.016)$ & $(0.023)$ & $(0.004)$ & $(0.007)$ \\
\hline \multirow[t]{2}{*}{ Constant } & $5.978^{* * *}$ & $5.576^{* * *}$ & $1.906^{* * *}$ & $1.196^{* * *}$ \\
\hline & $(0.725)$ & $(0.808)$ & $(0.171)$ & $(0.182)$ \\
\hline Observations & 717 & 717 & 717 & 717 \\
\hline R-squared & 0.206 & 0.072 & 0.301 & 0.055 \\
\hline
\end{tabular}

Note: The table shows baseline OLS regressions for 2011 of consumption expenditure and variety on manufactured goods (including processed food) and unprocessed food by travel time to Atsedemariam. Column 1 - 2 show the results for expenditures while columns $3-4$ show the results for variety in consumption. Standard errors are clustered at subsubkebele level. ${ }^{* * *} \mathrm{p}<0.01,{ }^{* *} \mathrm{p}<0.05,{ }^{*} \mathrm{p}<0.1$.

Table 2. How expenditure and variety of consumption change over travel time: 2011 
travel costs. The contrasting results between manufactured goods and unprocessed food are as expected. The variety in consumption is clearly responsive to the availability of manufactured goods as opposed to unprocessed foods. This is because as households obtain unprocessed food mostly from home production rather than traders, variety in unprocessed foods should not depend on fixed costs in transportation, and therefore not on travel time to the market town. In other words, the inelastic response of variety of unprocessed food to travel time indicates that the falling variety of manufactured goods over travel time to the central market is driven by transportation costs instead of say differential tastes of households which might also be associated with travel time to the market town.

In sum, both amount and variety of consumption of manufactures fall as travel time to the central market increases, undoubtedly driven by the combination of income, price and variety effects as explained earlier. We cannot disentangle these effects directly - but in the next section, we exploit a supply shock that isolates the combined variety and price effects, abstracting from the income effect. This allows us to document the sharp effect of the supply shock alone.

\section{A Further Quasi-experimental Design: A Crackdown on Un- licensed Traders}

As explained earlier (Stifel et al., 2016), the baseline 2011 survey was designed purposefully to examine the role of transport cost on household behaviour. The selected communities are homogeneous in land characteristics and productivity and the primary difference lies in the transport cost to Atsedemariam. Given the difficulties of migration and settlement, the pattern of settlement here has been unchanged for decades and conditional on this pattern, the comparison of variety and expenditures along this steep transport cost gradient can be interpreted as a causal response to distance or travel time.

\subsection{A crackdown on unlicensed traders}

The above results can be consolidated by a further quasi-experimental design about a crackdown on unlicensed traders in the survey area. The area is divided by a natural river. In late 2013, there was a crackdown on informal traders beyond this natural river boundary, effectively a supply shock for remote households relying on traders, both formal and informal. Traders are required to obtain a license to trade in particular goods and traders entering these hamlets from 
Atsedemariam are relatively easy to monitor. The concern of local authorities was that villages beyond the river boundary appeared to have a number of informal traders, moving goods without a license and also engaged in smuggling fertiliser, an input supposedly controlled by government extension workers. This crackdown meant that households beyond the river boundary and further away from the market were rationed mainly in processed and manufactured goods usually supplied by traders. 6

As in the baseline 2011 survey, the chosen households possess only a single route to the central market and are randomly distributed along the road; thus this design suggests the increase in travel cost is the only channel through which the ban on informal traders might affect the variety in consumption. The natural river boundary between hamlets which are affected and those who remain unaffected by the crackdown also made monitoring and enforcement easier for the authorities ensuring that the flow of goods was far lower than before. We label the households in these affected hamlets as "treated" by the crackdown. Hamlets which were affected by this negative supply shock include Abagedelga, Andaye, Abazonghe, Belweha and Borabord, are the treated while the remainder in hamlets closer to the market town are labelled the control. A sketch of treatment and control groups is also shown in the panel b of figure 1 . The sample consists of 279 treated and 438 control households.

By definition, the treatment group is farther from Atsedemariam than the control group. The budget share of monetary travel costs (i.e. the cost of renting a donkey per kilogram plus the opportunity cost of travel time) in expenditure on manufactured goods is $7 \%$ for the treatment and $4 \%$ for the control groups. As mentioned earlier, Stifel and Minten (2017) find no systematic differences in land characteristics and land productivity in the survey area. We pursue this comparison further across basic demographic variables and the measures of income and assets between the treatment and control groups in table 3. The value of household assets, proxied by value of livestock, does not differ significantly between control and treatment groups in the baseline in 2011. Furthermore, the insignificant difference in the change between treatment and control groups in value of livestock 8 after the crackdown on traders suggests that the potential decline in variety of consumption among treatment groups is not driven by the decrease in the underlying income in this group (i.e. an income effect). In fact, the value

\footnotetext{
${ }^{6}$ Skinner (2003) and Rozelle et al. (2003) discuss the similar role of traders until recently in China.

${ }^{7}$ The corresponding subkebeles are: Ababelewuha and Fantaye. All of these five sub-subkebeles are in the kebele Garasghe.

${ }^{8}$ Livestock are the main asset in this context, where alternative savings options are thin and farmers have only user rights to land.
} 
of livestock increases more (although not significantly) in the treatment group between 2011 and 2014, confirming that if variety in consumption decreased more in the treatment than in the control group in 2014, this can be largely ascribed to distance and travel costs rather than income effects.

However, there are demographic differences between control and treatment villages in table 3. Household size, number of male household members, age of household head and number of children (between age 5 and 15) in the household differ significantly in 2011 at baseline between treatment and control groups. This is unsurprising and again, this is in line with differences in behavioral outcomes driven by significant differences in transport costs. In what follows, we control for this set of demographic variables across households. More importantly, our difference-in-difference estimates mean that we can control for all time-invariant household and farm characteristics between treatment and control groups. Changes in expenditure patterns and variety can thus be cautiously interpreted as the effect of the supply shock in traders on household consumption through the change in travel cost rather than driven by other differences amongst households. 


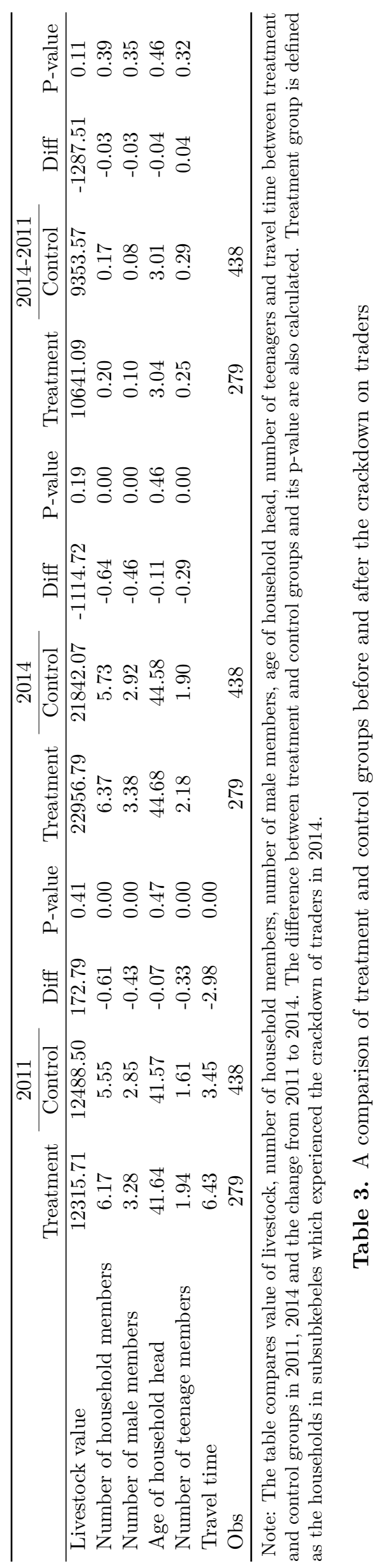




\subsection{Results: The fall in variety after the crackdown on traders}

As explained in the introduction, the standard trade framework (Melitz, 2003) delivers the prediction that the variety available in a village (and thus the potential variety in a household's consumption) will depend negatively on trade costs, proxied by travel costs to town in the presence of fixed costs to traders dealing in a small set of products. This framework delivers the prediction that the variety in expenditure should drop with increased distance from Atsedamariam. We thus expect: 1) the variety of expenditure should (relatively) drop significantly after the crackdown on traders in the treatment group compared with the control group, which we call the "treatment"; 2) variety in manufactured goods ought to respond sharply compared to the largely non-traded items in unprocessed food. The 717 households we study over the two years consist of 438 households in the control group and 279 in the treated group, with the treated group by definition, consisting of the remoter hamlets. Table 4 lists the difference by control and treatment villages in the share of households who do not consume a particular item in each of the two years. In short, it documents those items where the treatment group had lower variety in items consumed relative to the control group: a negative sign indicates that a higher proportion of households in the treated group do not consume that variety at all. While there is considerable heterogeneity in the varieties not consumed between the treated and control in 2011, after the crackdown, the share of treated households who do not consume a particular variety rises sharply almost universally, with an exception in their favour only apparent for cigarettes and batteries, both relatively light items that can be carried from Atsedemariam potentially by other households and neighbours going to market. Heavier items such as linens, books, sugar and soft drinks are the items that disappear from the consumption basket of treated households who might have suffered from the crackdown on traders.

A detailed look at changes in variety between 2011 and 2014 in treatment and control groups is in table 5. From 2011 to 2014, the variety in consumption increases in both groups. However, the increase in variety in the treatment group is significantly smaller than in the control group. In other words, the variety in consumption decreases in the treatment group relative to the control group. We note that this happens to both manufactured goods (including processed food) and unprocessed food. The puzzle here is the drop in variety in unprocessed food which is resolved by the difference-in-difference regressions (presented in the table below) where the difference in the change in variety between the two groups in unprocessed food is insignificant, suggesting that household fixed effects confound the behaviour of unprocessed foods. 


\begin{tabular}{lcc}
\hline & \multicolumn{2}{c}{ Control - treatment } \\
\cline { 2 - 3 } & 2011 & 2014 \\
\hline Coffee & $5.00 \%$ & $-0.45 \%$ \\
Birra & $0.49 \%$ & $-6.27 \%$ \\
Soft drink & $-1.05 \%$ & $-7.18 \%$ \\
Sugar & $-13.89 \%$ & $-24.27 \%$ \\
Salt & $0.10 \%$ & $0.33 \%$ \\
Cooking oil & $-7.98 \%$ & $-1.17 \%$ \\
Macaroni & $-0.68 \%$ & $-0.65 \%$ \\
Clothes & $0.51 \%$ & $2.36 \%$ \\
Kitchen equipment & $10.21 \%$ & $-8.74 \%$ \\
Linen & $3.79 \%$ & $-20.86 \%$ \\
Furniture & $0.36 \%$ & $-0.78 \%$ \\
Lamp & $-9.48 \%$ & $-12.81 \%$ \\
Cigarettes & $0.00 \%$ & $0.13 \%$ \\
Alcoholic beverage & $2.89 \%$ & $3.21 \%$ \\
Matches & $-3.06 \%$ & $-0.36 \%$ \\
Batteries & $5.82 \%$ & $3.20 \%$ \\
Candles & $0.16 \%$ & $-1.57 \%$ \\
Laundry soap & $2.71 \%$ & $-0.19 \%$ \\
Kerosene & $-16.05 \%$ & $-6.12 \%$ \\
Medicine & $19.68 \%$ & $0.54 \%$ \\
Books, pens, uniforms & $-3.12 \%$ & $-22.25 \%$ \\
Hand soap & $-10.77 \%$ & $-22.17 \%$ \\
Sendel and matent & $0.02 \%$ & Soft drinks, sugar, cooking oil, marcaroni, \\
\hline 0\% control $<$ treatment in the baseline: & lamp, matches, kerosene, books, soap. \\
0\% increase in 2014 for treatment: & Coffee, birra, soft drink, sugar, cooking oil, \\
& macaroni, kitchen equipment, linen, \\
& furniture, lamp, matches, candles, soap, \\
\hline kerosene, books, cosmetics. \\
\hline
\end{tabular}

Note: The first column shows the difference in share of households who have zero consumption on each item between treatment and control groups in 2011, while the next column shows how the difference is affected by the crackdown on traders in 2014. At the end of the table there is a list of items where the share of households with zero consumption on the corresponding item is smaller among the control than the treatment groups in the baseline, and a list of items where the share of households with zero consumption on the corresponding item relatively increases in 2014 for treatment group compared with the control group. $0 \%$ indicates the share of households with zero consumption on the corresponding items.

Table 4. Difference in the share of households who have zero consumption on specific items between control and treatment groups 





We explore the impact of the crackdown more formally, using a difference-in-difference specification as below. In equation 2, for each household $i$ in hamlet $s$ in year $t$, we have:

$$
Y_{i s t}=\alpha+\beta T_{t} * D_{s}+\eta D_{s}+\gamma T_{t}+\phi X_{i s t}+\epsilon_{i s t}
$$

As before, $Y_{i s t}$ is variety in consumption (measured by number of items purchased). $\beta$ is the coefficient of interest. $T_{t}$ equals one for observations in year 2014 and zero in year 2011. $D_{s}$ equals one (zero) if sub-subkebele $s$ is in the treatment (control) group, while $X_{i s t}$ refers to the same set of control variables 9 as before. We expect $\beta$ is significantly negative for the variety of manufactured goods. Similar to the analysis earlier, since unprocessed foods are less likely to have been affected by the crackdown, we expect to see little or no effect on variety for them. Standard errors in all these regressions are clustered at the level of the hamlet.

One potential threat to the difference-in-difference framework is that there might be a process of general development between 2011 and 2014 in the sampling area which increases variety in both groups but much less so in distant locations. If the development is skewed across space and is independent of the crackdown on traders, the difference between the treatment and control groups between the two years is not attributable to this regulation policy. Assuming that such growth affects the availability of manufactured goods and unprocessed foods symetrically, this is not likely to be a concern if we do not find any difference in the change in variety between treatment and control groups for unprocessed food. There might also be some general development in infrastructure which reduces travel costs disproportionably between treatment and control groups. But in this setting there is no change in (the lack of) a road in the survey area in both years 10 . We do find that varieties in both manufactured goods and unprocessed food increase from 2011 to 2014 in both treatment and control groups consistent with the general increase in growth in Ethiopia and in these villages over time. However, as we show below, this potential confounding factor moved in a similar fashion for the two groups as there is no difference in the change in variety of unprocessed food in consumption, making it unlikely that there are asymmetric growth effects.

\footnotetext{
${ }^{9} X_{i s t}$ refers to a set of control variables such as household assets (measured by the value of livestock), household size, number of male household members, number of children between 5 and 15 years of age, the age of household head and quadratic terms using the demographic variables.

${ }^{10}$ Another possibility is that a change in the design of the survey or a differential efficiency of the surveyors made them better able to measure consumption in 2014. We do not think this is plausible since identical survey instruments were used in both rounds and the identity of surveyors and survey manager stayed the same over the two years. In particular, the overall pool of varieties in consumption is the same over the two years.
} 


\begin{tabular}{|c|c|c|c|c|}
\hline \multirow[b]{3}{*}{ VARIABLES } & \multirow{2}{*}{\multicolumn{2}{|c|}{ Expenditure }} & \multicolumn{2}{|r|}{ [4] } \\
\hline & & & \multicolumn{2}{|c|}{ Variety } \\
\hline & $\begin{array}{c}\text { Manufactured } \\
+ \text { processed food }\end{array}$ & Unprocessed food & $\begin{array}{c}\text { Manufactured } \\
+ \text { processed food }\end{array}$ & Unprocessed food \\
\hline \multirow[t]{2}{*}{ Treat $*$ year14 } & -0.193 & -0.189 & $-0.074^{* *}$ & -0.111 \\
\hline & $(0.146)$ & $(0.255)$ & $(0.034)$ & $(0.161)$ \\
\hline \multirow[t]{2}{*}{ Treat } & $-0.260^{* *}$ & -0.098 & -0.027 & 0.020 \\
\hline & $(0.112)$ & $(0.117)$ & $(0.020)$ & $(0.071)$ \\
\hline \multirow[t]{2}{*}{ Year14 } & $0.530^{* * *}$ & $0.641^{* * *}$ & $0.087^{* * *}$ & $0.263^{* * *}$ \\
\hline & $(0.114)$ & $(0.154)$ & $(0.031)$ & $(0.041)$ \\
\hline \multirow[t]{2}{*}{ Livestock value } & $0.106^{* * *}$ & $0.073^{* *}$ & $0.033^{* * *}$ & 0.014 \\
\hline & $(0.023)$ & $(0.034)$ & $(0.010)$ & $(0.013)$ \\
\hline \multirow[t]{2}{*}{ No. of household members } & $0.218^{* *}$ & $0.277^{*}$ & $0.111^{* * *}$ & 0.012 \\
\hline & $(0.103)$ & $(0.139)$ & $(0.024)$ & $(0.048)$ \\
\hline \multirow[t]{2}{*}{ No. of male members } & 0.102 & -0.003 & 0.039 & 0.055 \\
\hline & $(0.085)$ & $(0.120)$ & $(0.029)$ & $(0.041)$ \\
\hline \multirow[t]{2}{*}{ Age of household head } & $0.027^{*}$ & 0.022 & 0.000 & 0.005 \\
\hline & $(0.014)$ & $(0.016)$ & $(0.003)$ & $(0.006)$ \\
\hline \multirow[t]{2}{*}{ No. of teenagers } & -0.054 & $-0.147^{*}$ & 0.002 & $-0.057 * * *$ \\
\hline & $(0.070)$ & $(0.083)$ & $(0.011)$ & $(0.019)$ \\
\hline \multirow[t]{2}{*}{ No. of household members sqr } & -0.011 & $-0.017^{*}$ & $-0.007 * * *$ & -0.001 \\
\hline & $(0.007)$ & $(0.009)$ & $(0.002)$ & $(0.003)$ \\
\hline \multirow[t]{2}{*}{ No. of male members sqr } & -0.008 & 0.003 & -0.004 & -0.005 \\
\hline & $(0.010)$ & $(0.013)$ & $(0.004)$ & $(0.004)$ \\
\hline \multirow[t]{2}{*}{ Age of household head sqr } & $-0.000^{*}$ & -0.000 & -0.000 & -0.000 \\
\hline & $(0.000)$ & $(0.000)$ & $(0.000)$ & $(0.000)$ \\
\hline \multirow[t]{2}{*}{ No. of teenagers sqr } & -0.002 & 0.026 & -0.000 & $0.008^{* *}$ \\
\hline & $(0.012)$ & $(0.016)$ & $(0.002)$ & $(0.004)$ \\
\hline \multirow[t]{2}{*}{ Constant } & $5.315^{* * *}$ & $5.052^{* * *}$ & $1.827^{* * *}$ & $1.374^{* * *}$ \\
\hline & $(0.332)$ & $(0.337)$ & $(0.095)$ & $(0.087)$ \\
\hline Observations & 1,434 & 1,434 & 1,434 & 1,434 \\
\hline R-squared & 0.219 & 0.110 & 0.313 & 0.110 \\
\hline
\end{tabular}

Note: The table shows difference-in-difference regressions with data on 2011 and 2014 of expenditure on manufactured goods (including processed food) and unprocessed food. Column $1-2$ show the results of amount of expenditure while columns $3-4$ show the results of variety of expenditure. "Treat" is a dummy variable which equals 1 if the household belongs to the treatment group. Treatment group is defined as the households in subsubkebeles which experienced the crackdown of traders in 2014. "Year14" equals 1 if data comes from 2014 survey. Treat * year 14 is the interaction term between the two which captures treatment effect. Standard errors are clustered at subsubkebele level. ${ }^{* * *} \mathrm{p}<0.01,{ }^{* *} \mathrm{p}<0.05,{ }^{*} \mathrm{p}<0.1$.

Table 6. The effect of the crackdown on traders on different categories of consumption

The main results from the specification above are in table 6. Columns 1-2 report the effect of the supply shock of traders on the amount of expenditure while the dependent variable in column 3-4 is variety in consumption. Household characteristics such as number of household members, number of male members, number of children, age of household head and their quadratic terms are included in all the columns. We focus on the interaction term between treatment and year for interpretation.

Column 1-2 reveals that the crackdown on traders has no significant effect on the amount of expenditure in both consumption categories, which indicates that the negative supply shock of traders did not affect household income differently between treatment and control groups. In columns 3-4, we observe that the variety of manufactured goods sees a decrease in the 
treatment group relative to the control group after the crackdown on traders but the gap between treatment and control groups is not observed for variety in unprocessed foods. As the variety of manufactured goods available to households is directly affected by existence of traders, the treatment effect arises from variety but not expenditure. To quantify the importance of changes in consumption of manufactured goods, we note that the coefficient of the interaction term in column 3 is -0.0744 and the coefficient of the year dummy is 0.0874 . This means that the variety in consumption of manufactured goods increases from 2011 to 2014 by 0.0874 units in general. Being in the treatment group, however, reduces this increase by 0.0744 units. All these results are consistent with our prediction that a crackdown on traders leads to a decline in the variety of consumption, in particular in the variety in manufactured goods.

The analysis above isolates a combined price and variety effect, abstracting from an income effect, since the fall in variety is simply due to the rationing in trade in manufactures. We attempt to extend this to isolate a pure variety effect of the crackdown, by comparing treatment and control households just across the river boundary. Since the difference in travel costs ought to be small at the border and the income effects are negligible by construction, the fall in variety can be ascribed to the crackdown alone. Table 7 shows the difference in the change of variety between treatment and control groups at the hamlets on either side of the border 11 . We note here that the gap in variety in manufactured goods (including processed food) between treatment and control groups is still significant. Compared with table 6, the magnitude of the gap in the change of variety between treatment and control groups is three times larger at the border, which can largely be ascribed to the variety effect alone.

To emphasise that the gap in variety between treatment and control groups at the border is mainly attributable to the variety effect instead of the price effect, we focus on the border between the control and treatment villages and draw figure 3. The left panel in figure 3 shows that there is indeed a jump in travel time across the border from control to treatment groups. In contrast, in the right panel, there is no jump in stone price index, which means going from the control to the treatment group affects travel time but not price at the border, suggesting that the focus on the border villages helps separate the price and variety effect.

\footnotetext{
${ }^{11}$ The "border" is defined as hamlets which are at the bordering areas between treatment and control villages. Bordering hamlets in the treatment group include Abagedelga and Andaye. Bordering hamlets in the control group include Asehra Shiroye and Golemeye.
} 


\begin{tabular}{|c|c|c|}
\hline VARIABLES & $\begin{array}{c}1] \\
\text { Expenditure }\end{array}$ & $\begin{array}{c}2] \\
\text { Variety }\end{array}$ \\
\hline Treat * year14 & $\begin{array}{l}-0.253 \\
(0.173)\end{array}$ & $\begin{array}{c}-0.229^{* *} \\
(0.059)\end{array}$ \\
\hline Treat & $\begin{array}{l}-0.242 \\
(0.121)\end{array}$ & $\begin{array}{l}0.087^{*} \\
(0.030)\end{array}$ \\
\hline Year14 & $\begin{array}{l}0.664^{* *} \\
(0.133)\end{array}$ & $\begin{array}{l}0.187^{* *} \\
(0.051)\end{array}$ \\
\hline Livestock value & $\begin{array}{c}0.167 \\
(0.099)\end{array}$ & $\begin{array}{c}0.057 \\
(0.036)\end{array}$ \\
\hline No. of household members & $\begin{array}{c}0.168 \\
(0.124)\end{array}$ & $\begin{array}{c}0.069 \\
(0.037)\end{array}$ \\
\hline No. of male members & $\begin{array}{l}0.422^{*} \\
(0.147)\end{array}$ & $\begin{array}{c}0.152 \\
(0.072)\end{array}$ \\
\hline Age of household head & $\begin{array}{c}0.041 \\
(0.020)\end{array}$ & $\begin{array}{c}0.004 \\
(0.008)\end{array}$ \\
\hline No. of teenagers & $\begin{array}{l}-0.078 \\
(0.136)\end{array}$ & $\begin{array}{l}-0.014 \\
(0.043)\end{array}$ \\
\hline No. of household member sqr & $\begin{array}{l}-0.003 \\
(0.008)\end{array}$ & $\begin{array}{l}-0.004 \\
(0.002)\end{array}$ \\
\hline No. of male member sqr & $\begin{array}{l}-0.058^{*} \\
(0.025)\end{array}$ & $\begin{array}{l}-0.022 \\
(0.009)\end{array}$ \\
\hline Age of households head sqr & $\begin{array}{l}-0.000 \\
(0.000)\end{array}$ & $\begin{array}{l}-0.000 \\
(0.000)\end{array}$ \\
\hline No. of teenagers sqr & $\begin{array}{l}-0.012 \\
(0.027)\end{array}$ & $\begin{array}{c}0.007 \\
(0.006)\end{array}$ \\
\hline Constant & $\begin{array}{c}4.029 * * * \\
(0.550)\end{array}$ & $\begin{array}{c}1.435^{* * *} \\
(0.168)\end{array}$ \\
\hline Observations & 326 & 326 \\
\hline R-squared & 0.287 & 0.380 \\
\hline
\end{tabular}

Note: The table shows difference-in-difference regressions in 2011 and 2014 of expenditure on manufactured goods (including processed food) for the villages at the border of the treatment/control groups. Column 1 shows the results for expenditures while column 2 shows the results for variety in expenditure. Standard errors are clustered at hamlets level. *** $\mathrm{p}<0.01, * *$ $\mathrm{p}<0.05,{ }^{*} \mathrm{p}<0.1$.

Table 7. The effect of the crackdown on traders on manufactured goods at the bordering villages 


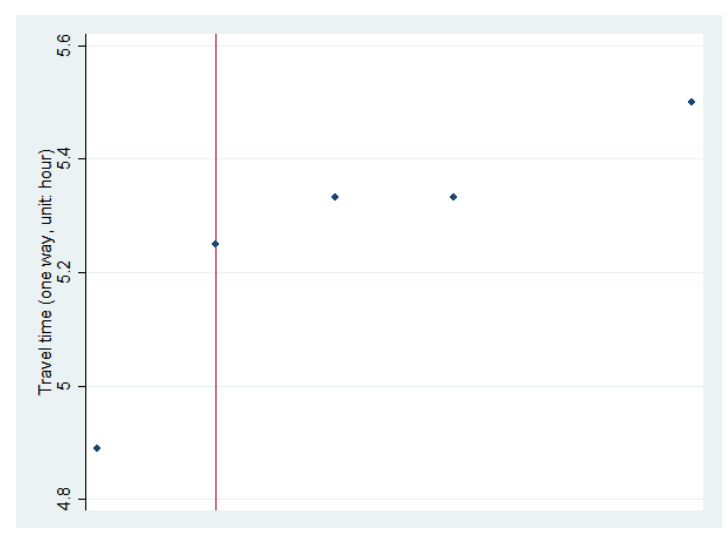

(a) Travel time

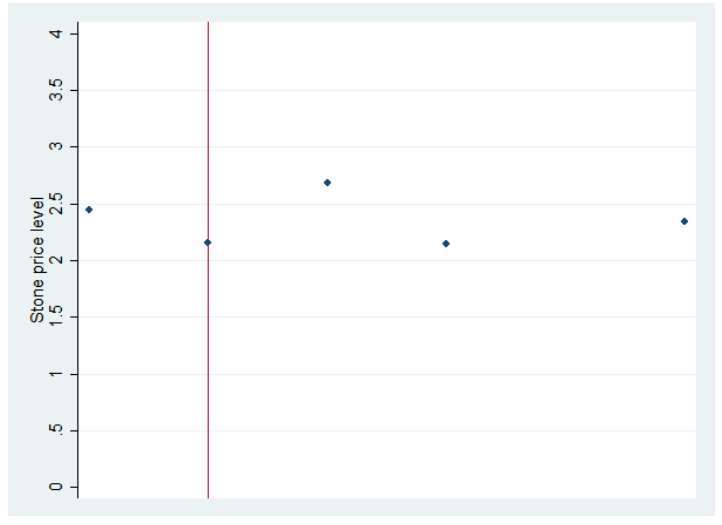

(b) Stone Price Index

Notes: These figures capture the travel time and stone price index in treatment and control groups at the border. The left hand side depicts travel time and the right hand side depicts stone price index. The red line indicates where the treatment group starts.

Figure 3. Travel time and stone price index in bordering treatment and control groups

\subsection{Robustness checks}

As a robustness check on the effects of distance on variety, we first replicate the regression of the number of varieties consumed against travel time for 2011, using an alternative measure to capture travel cost. It is the monetary value of travel time which takes into account the heterogeneity in cost of renting a donkey and wage across different hamlets. It includes the cost of renting a donkey per kilogram and the median harvest-period wage in the village multiplying travel time. We focus only on the amount of expenditure in this section as travel cost is not explicitly included in difference-in-difference regressions. Table 8 replicates the results on baseline regressions of the amount of expenditure by replacing travel time with monetary cost. Consistent with all the results in table 2, the coefficients on monetary travel cost remain negatively significant for expenditure on both manufactured goods and unprocess food. Note that only the variety in manufactured goods responds to changes in travel cost (measured by monetary cost here).

In addition, as a second robustness check, we also examine the difference-in-difference regression with household fixed effects. Based on equation 2, we include these fixed effects denoted by $u_{i s}$ which capture all time-invariant characteristics at the household level. If these characteristics differ between the treatment and control groups, they might confound our estimate of the treatment effect. The other variables are defined in the same way as in equation 2. $D_{s}$ is omitted as it is part of the household fixed effect. Standard errors are clustered at the level of the hamlet. 


\begin{tabular}{|c|c|c|c|c|}
\hline \multirow[b]{3}{*}{ VARIABLES } & \multirow{2}{*}{\multicolumn{2}{|c|}{ Expenditure }} & {$[3]$} & \multirow[b]{2}{*}{ lety } \\
\hline & & & Variety & \\
\hline & $\begin{array}{c}\text { Manufactured } \\
+ \text { processed food }\end{array}$ & Unprocessed food & $\begin{array}{c}\text { Manufactured } \\
+ \text { processed food }\end{array}$ & Unprocessed food \\
\hline \multirow[t]{2}{*}{ Travel cost } & $-0.398^{* * *}$ & $-0.339^{* *}$ & $-0.052^{* * *}$ & 0.049 \\
\hline & $(0.110)$ & $(0.147)$ & $(0.017)$ & $(0.049)$ \\
\hline \multirow[t]{2}{*}{ Livestock value } & $0.143^{* * *}$ & $0.086^{*}$ & $0.041^{* * *}$ & 0.016 \\
\hline & $(0.032)$ & $(0.050)$ & $(0.014)$ & $(0.015)$ \\
\hline \multirow[t]{2}{*}{ No. of household members } & $0.252^{* *}$ & $0.221^{*}$ & $0.093^{* * *}$ & 0.015 \\
\hline & $(0.096)$ & $(0.127)$ & $(0.025)$ & $(0.052)$ \\
\hline \multirow{2}{*}{ No. of male household members } & 0.042 & -0.038 & $0.057 * *$ & 0.031 \\
\hline & $(0.082)$ & $(0.106)$ & $(0.026)$ & $(0.037)$ \\
\hline \multirow[t]{2}{*}{ Age of household head } & 0.015 & 0.038 & -0.001 & 0.014 \\
\hline & $(0.023)$ & $(0.032)$ & $(0.004)$ & $(0.009)$ \\
\hline \multirow[t]{2}{*}{ No. of teenagers } & -0.096 & -0.203 & 0.001 & $-0.088^{* *}$ \\
\hline & $(0.109)$ & $(0.134)$ & $(0.022)$ & $(0.040)$ \\
\hline \multirow[t]{2}{*}{ No. of household members sqr } & $-0.013^{* *}$ & $-0.014^{*}$ & $-0.006^{* * *}$ & -0.002 \\
\hline & $(0.006)$ & $(0.008)$ & $(0.002)$ & $(0.003)$ \\
\hline \multirow[t]{2}{*}{ No. of male members sqr } & -0.002 & 0.007 & $-0.007 * *$ & -0.003 \\
\hline & $(0.011)$ & $(0.011)$ & $(0.003)$ & $(0.004)$ \\
\hline \multirow[t]{2}{*}{ Age of household head sqr } & -0.000 & -0.000 & -0.000 & $-0.000^{* *}$ \\
\hline & $(0.000)$ & $(0.000)$ & $(0.000)$ & $(0.000)$ \\
\hline \multirow[t]{2}{*}{ No. of teenagers sqr } & 0.011 & $0.050 * *$ & 0.003 & $0.016^{* *}$ \\
\hline & $(0.016)$ & $(0.023)$ & $(0.004)$ & $(0.007)$ \\
\hline \multirow[t]{2}{*}{ Constant } & $6.822^{* * *}$ & $6.314^{* * *}$ & $2.007 * * *$ & $1.030^{* * *}$ \\
\hline & $(0.909)$ & $(1.082)$ & $(0.182)$ & $(0.247)$ \\
\hline Observations & 717 & 717 & 717 & 717 \\
\hline R-squared & 0.201 & 0.070 & 0.299 & 0.058 \\
\hline
\end{tabular}

Note: The table shows baseline OLS regressions for 2011 of expenditures and variety in manufactured goods (including processed food) and unprocessed food by travel cost which is measure by cost of renting a donkey plus opportunity cost of time to Atsedemariam. Column $1-2$ show the results of total expenditures while columns $3-4$ show the results of variety in expenditure. Standard errors are clustered at village level. ${ }^{* * *} \mathrm{p}<0.01, * * \mathrm{p}<0.05,{ }^{*} \mathrm{p}<0.1$.

Table 8. Robustness check: the effects on consumption using a different measure of travel cost (cost of donkeys plus opportunity cost of time) in 2011 


\begin{tabular}{|c|c|c|c|c|}
\hline \multirow[b]{3}{*}{ VARIABLES } & [1] & {$[2]$} & [3] & {$[4]$} \\
\hline & \multicolumn{2}{|c|}{ Expenditure } & \multicolumn{2}{|c|}{ Variety } \\
\hline & $\begin{array}{c}\text { Manufactured } \\
+ \text { processed food }\end{array}$ & Unprocessed food & $\begin{array}{c}\text { Manufactured } \\
+ \text { processed food }\end{array}$ & Unprocessed food \\
\hline \multirow[t]{2}{*}{ Treat $*$ year 14} & -0.179 & -0.177 & $-0.071^{*}$ & -0.112 \\
\hline & $(0.147)$ & $(0.265)$ & $(0.035)$ & $(0.162)$ \\
\hline \multirow[t]{2}{*}{ Year14 } & $0.526^{* * *}$ & $0.633^{* * *}$ & $0.084^{* * *}$ & $0.263^{* * *}$ \\
\hline & $(0.112)$ & $(0.144)$ & $(0.031)$ & $(0.037)$ \\
\hline Household FE & YES & YES & YES & YES \\
\hline Time-varying Characteristics & YES & YES & YES & YES \\
\hline \multirow[t]{2}{*}{ Constant } & $5.354^{* * *}$ & $5.701^{* * *}$ & $1.748^{* * *}$ & $1.555^{* * *}$ \\
\hline & $(0.644)$ & $(0.977)$ & $(0.201)$ & $(0.272)$ \\
\hline Observations & 1,434 & 1,434 & 1,434 & 1,434 \\
\hline R-squared & 0.194 & 0.125 & 0.148 & 0.165 \\
\hline No. of groups & 717 & 717 & 717 & 717 \\
\hline
\end{tabular}

Note: The table shows difference-in-difference regressions with data on 2011 and 2014 of expenditure on manufactured goods (including processed food) and unprocessed food incorporating household fixed effects. Column 1 - 2 show the results of amount of expenditure while columns 3 - 4 show the results of variety of expenditure. "Treat" is a dummy variable which equals 1 if the household belongs to the treatment group. Treatment group is defined as the households in subsubkebeles which experienced the crackdown of traders in 2014. "Year14" equals 1 if data comes from 2014 survey. Treat * year 14 is the interaction term between the two which captures treatment effect. We include both household fixed effects and time-varying household characteristics like the value of livestock. Standard errors are clustered at subsubkebele level. *** $\mathrm{p}<0.01,{ }^{* *} \mathrm{p}<0.05,{ }^{*} \mathrm{p}<0.1$.

Table 9. The effect of the crackdown on traders on different categories of consumption: fixed effect regressions

$$
Y_{i s t}=\alpha+\beta T_{t} * D_{s}+\gamma T_{t}+\phi X_{i s t}+u_{i s}+\epsilon_{i s t}
$$

The results are reported in table 9. The first two columns show the results of the amount of expenditure on manufactured goods (including processed food) and unprocessed food, respectively. Columns 3 and 4 present the results of the variety of expenditure on the corresponding two categories. Compared with the main results in table 6, the results with household fixed effect stay robust. The treatment effect (which is captured by the coefficient of the interaction term between the group dummy and the time dummy) is negative and significant only for the variety of manufactured goods. The magnitude of the treatment effect is also similar between the two regressions. The coefficient of the interaction term between the group dummy and the time dummy is -0.074 in table 6 and -0.071 in table 9 . In brief, our results are robust to using the fixed effect specification to isolate the impact of the crackdown.

\section{Conclusion and discussion}

We examine the effect of market access, captured by both travel time to the central market and accessibility to traders, on the variety in household consumption of manufactures using a 
unique data on a set of remote villages in northwestern Ethiopia. We examine this question in a setting where farm households are homogenous in terms of their main productive asset, land, and its productivity, but where other outcomes vary, driven largely by the time to travel to the nearest market town. Traders also move goods from town to village. In particular, they incur a fixed cost of a license to carry particular groups of items in addition to the cost of travel from town to village which serves to reduce availability of variety in remoter areas. We use a purpose-designed survey to counter the difficulty that roads are usually not randomly placed, thus ensuring that we can ascribe the lower variety in consumption baskets in remoter areas to the costs of access to markets in the main.

We find that variety in the household consumption of manufactured goods decreases with distance and travel time to the central market. We are also able to use a crackdown on informal traders who have operated without a license to investigate the consequences on varieties consumed by more remote households no longer served by such traders. Using a differencein-difference approach, we find that variety of manufactured goods decreases relatively and substantially in these more remote households compared with unaffected households. In brief, remoteness from markets and restrictions on trade reduce the variety in household consumption. 


\section{References}

Adam, C., Bevan, D., and Gollin, D. (2018). Rural-Urban Linkages, Public Investment and Transport Costs: The Case of Tanzania. World Development, 109:497-510.

Anderson, J. E. and van Wincoop, E. (2004). Trade Costs. Journal of Economic Literature, 24(3):691-751.

Bird, K., McKay, A., and Shinyekwa, I. (2010). Isolation and Poverty: the Relationship Between Spatially Differentiated Access To Goods and Services and Poverty. ODI/CPRC Working Paper Series (ODI WP322, CPRC WP162), pages 1-38.

Chamberlin, J. and Jayne, T. (2013). Unpacking the Meaning of 'Market Access': Evidence from Rural Kenya. World Development, 41:245-264.

Dercon, S., Gilligan, D. O., Hoddinott, J. H., and Woldehanna, T. (2009). The Impact of Agricultural Extension and Roads on Poverty and Consumption Growth in Fifteen Ethiopian Villages. American Journal of Agricultural Economics, 91(4):1007-1021.

Dihel, N. (2011). Beyond the Nakumatt Generation: Distribution Services in East Africa. World Bank Africa Trade Policy Notes, 26:1-12.

Dixit, A. K. and Stiglitz, J. E. (1977). Monopolistic Competition and Optimun Product Diversity. The American Economic Review, 67(3):297-308.

Donaldson, D. and Hornbeck, R. (2016). Railroads and American Economic Growth: A "Market Access" Approach. The Quarterly Journal of Economics, 131(2):799-858.

Fafchamps, M. and Shilpi, F. (2008). Subjective Welfare, Isolation and Relative Consumption. Journal of Development Economics, 86(1):43-60.

Gollin, D. and Rogerson, R. (2014). Subjective Welfare, Isolation and Relative Consumption. Journal of Development Economics, 107:38-48.

Gunning, J. W., Krishnan, P., and Mengistu, A. T. (2018). Fading Choice: Transport Costs and Variety in Consumer Goods. CEPR Discussion Paper 12910.

Jacoby, H. G. (2000). Access to Markets and the Benefits of Rural Roads. The Economic Journal, 110:713-737. 
Jacoby, H. G. and Minten, B. (2009). On Measuring the Benefits of Lower Transport Costs. Journal of Development Economics, 89(1):28-38.

Khandker, S. R., Bakht, Z., and Koolwal, G. B. (2009). The Poverty Impact of Rural Roads: Evidence from Bangladesh. Economic Development and Cultural Change, 57(4):685-722.

Krugman, P. (1979). Increasing Returns, Monopolistic Competition, and International Trade. Journal of International Economics, 9(4):469-479.

Krugman, P. (1980). Scale Economies, Product Differentiation, and the Pattern of Trade. The American Economic Review, 70(5):950-959.

Li, N. (2017). An Engel Curve for Variety, Mimeo, at: http : //individual.utoronto.ca/econ_nick_li/engel\%20curve\%20variety\%20v2.pdf.

Melitz, M. J. (2003). The Impact of Trade on Intra-Industry Reallocations and Aggregate Industry Productivity. Econometrica, 71(6):1695-1725.

Rozelle, S., Huang, J., and Benziger, V. (2003). Continuity and Change in China's Rural Periodic Markets. The China Journal, 49:89-115.

Skinner, C. (2008). Street Trade in Africa: A Review. WIEGO Working Paper 5.

Skinner, W. (2003). Marketing and Social Structure in Rural China. Journal of Asian Studies, 24:3-42; 195-228; 363-399.

Stifel, D. and Minten, B. (2008). Isolation and Agricultural Productivity. Agricultural Economics, 39(1):1-15.

Stifel, D. and Minten, B. (2017). Market Access, Well-being, and Nutrition: Evidence from Ethiopia. World Development, 90:229-241.

Stifel, D., Minten, B., and Koro, B. (2016). Economic Benefits and Returns to Rural Feeder Roads: Evidence from a Quasi Experimental Setting in Ethiopia. Journal of Development Studies, 52(9):1335-1356. 